\title{
Prevalence of Malocclusion in Western Nepal
}

\author{
Dr Prakash Baral \\ Associate Professor, Gandaki Medical College, Pokhara, Nepal \\ Correspondence: Dr Prakash Baral; Email: prakashbaral2002@hotmail.com
}

\section{ABSTRACT}

Introduction: Malocclusion is the improper relationship of maxillary and mandibular teeth. The prevalence of malocclusion varies in different populations of the world.

Objective: To study the prevalence of malocclusion in western part of Nepal and to evaluate the gender variation in occurrence of malocclusion.

Materials \& Method: A total of 1284 subjects were studied. Out of them 656 were male and 628 were female. Intra-oral examination was carried out to assess occlusal types of Class I, II, III according to Angle's classification of malocclusion, and various occlusal characteristics like crowding, spacing, cross-bite, open-bite and deep bite were recorded. Gender variation in malocclusion characteristics were tested using chi-square test $(p<0.05)$.

Result: The present study showed that Class I occlusion type with malocclusion was more prevalent than Class II and Class III malocclusions. Class I was seen in $71.5 \%$, Class II div 1 in $20.7 \%$, Class II div 2 in $3.9 \%$ cases and Class III in $4.1 \%$ cases. Among the occlusal characteristics; crowding (61.3\%), deep bite (29.5\%) and spacing (10.5\%) were most prevalent.

Conclusion: Class I malocclusion was most prevalent type of malocclusion in western Nepalese subjects. There was no significant gender dimorphism between male and female in prevalence of various malocclusion characteristics.

Keywords: gender variation, malocclusion, prevalence

\section{INTRODUCTION}

Malocclusion is the improper relationship of maxillary and mandibular teeth. It causes impairment of oral health, functions, esthetics and also affects the psychology of the individual. The prevalence of malocclusion varies among different populations of the world. This variation is attributed to genetic, racial and environmental aspects. ${ }^{1-7}$ Nepal is a country with diverse ethnic population, culture, climate and environment. The distribution of different malocclusions in Nepal might be different from rest of the world. Hence the objective of the present study was to study the prevalence of malocclusion in western part of Nepal and to find out the variations in prevalence of malocclusion between male and female subjects.

\section{MATERIALS AND METHOD}

A cross-sectional study was conducted among 1284 individuals in Western region of Nepal. Out of them 656 were male and 628 were female. Samples were stratified into male and female strata.

Sample size was calculated as 969 using the formula: $N=4 p q / L^{2}$.
[Where, $p=$ prevalence rate obtained from previous study; ${ }^{8}$ thus considered as $62.28 \%$. $q=1-p ; L=$ permissible error in the estimation of ' $p$ '. In this case; $L=5 \%$ of $62.28=3.114$ ]

However, due to availability of more number of samples, the present study was conducted among 1284 subjects.

Subjects of all age groups with complete permanent dentitions were included in the study. Subjects with grossly decayed teeth, having the history of tooth extraction and orthodontic treatment in the past were excluded from the study. People of different communities and ethnic groups like Brahmin, Chhetri, Magar, Gurung, Tamang, Rai, Limbu, Newar, Madhesi, Tharu etc residing in different districts of Western Region were studied.

Clinical examination was done on subjects who attended dental OPD's of hospitals, dental clinics, and those who attended school oral health program and community dental camps held in different parts of Western Region like Kaski, Tanahu, Lamjung, Gorkha, Syangja, Myagdi, Baglung, Parbat, Palpa and Nawalparasi districts. Intra-oral examination was carried out directly with the help of mouth mirror and probe. Examination was done by the author alone who served as the 
Table 2- Pattern of maxillary canine impactions

\begin{tabular}{|c|c|c|c|c|c|c|}
\hline \multicolumn{2}{|r|}{ Parameter } & $\begin{array}{c}\text { Total } \\
(\mathrm{N}=1284)\end{array}$ & $\begin{array}{c}\text { Percentage } \\
(\%)\end{array}$ & $\begin{array}{c}\text { Male } \\
(\mathrm{N}=656)\end{array}$ & $\begin{array}{l}\text { Female } \\
(\mathrm{N}=628)\end{array}$ & $p$-Value \\
\hline \multirow{4}{*}{ Occlusal type } & Class I & 919 & 71.5 & 489 & 430 & 0.28 \\
\hline & Class II div 1 & 266 & 20.7 & 123 & 143 & 0.31 \\
\hline & Class II div 2 & 51 & 3.9 & 30 & 21 & 0.36 \\
\hline & Class III & 52 & 4.1 & 32 & 20 & 0.18 \\
\hline \multirow{7}{*}{$\begin{array}{l}\text { Occlusal } \\
\text { characteristic }\end{array}$} & Crowding & 787 & 61.3 & 401 & 386 & 0.16 \\
\hline & Spacing including midline diastema & 135 & 10.5 & 65 & 70 & 0.28 \\
\hline & Anterior crossbite & 81 & 6.3 & 46 & 35 & 0.43 \\
\hline & Posterior crossbite & 45 & 3.5 & 26 & 19 & 0.48 \\
\hline & Open bite & 114 & 8.9 & 63 & 51 & 0.54 \\
\hline & Deep bite & 379 & 29.5 & 194 & 185 & 0.55 \\
\hline & Scissors bite & 2 & 0.2 & 1 & 1 & 1.0 \\
\hline
\end{tabular}

(Not significant $p>0.05$ )

dental surgeon, it avoided inter-observer variation.

The subjects were assessed for occlusal types like Class I, II, III molar relation according to Angle's classification and various occlusal characteristics like crowding, spacing, crossbite, open bite, deep bite and scissor bite. The Class I category included both normal occlusion and malocclusion. The findings were recorded on a performa sheet.

The data were entered and statistical analysis was carried out using SPSS Version 16. Chi-square test was applied to test the significant difference as the data were in proportion (frequency percentage). The comparison was made between male and female samples for the variables of occlusal types (Angle's classification) and occlusal characteristics (crowding, spacing, crossbite, open bite, deep bite and scissor bite).

\section{RESULT}

Out of the total of 1284 western Nepalese subjects studied; the male to female ratio was 1.04:1. The age range was 13-63 years, and mean age was 38 years. The occlusal types according to Angle's classification of malocclusion and various occlusal characteristics are recorded in Table 1.

The present study showed Angle's Class I molar relation including normal occlusion and malocclusion was more prevalent than Class II and Class III malocclusions. Class | molar relation was found in $71.5 \%$, Class || div 1 in $20.7 \%$, Class II div 2 in $3.9 \%$ and Class III in $4.1 \%$ cases.

Crowding was seen more frequently than spacing. 61.3\% of the total subjects had crowding where as $10.5 \%$ had spacing. Anterior crossbite occurred more frequently than posterior crossbite cases. Out of total samples, $6.3 \%$ subjects had anterior crossbite and $3.5 \%$ had posterior crossbite.

Likewise, deep bite occurred more frequently than open bite; $29.5 \%$ showed deep bite whereas $8.9 \%$ showed open bite. Scissor bite was found to be the least common occlusal characteristic which occurred only in $0.2 \%$ cases.

The present study showed no significant difference between male and female samples in occlusal types and occlusal characteristics studied.

\section{DISCUSSION}

The present report on malocclusion status and occlusal characteristics are comparable to other studies carried on Nepalese population. Shrestha BK et al reported malocclusion status of high school students in Kathmandu valley and found the prevalence of normal occlusion in $27 \%$ and malocclusion in $73 \%$. In their study; Class I malocclusion was found in $59 \%$, Class II in $25 \%$ and Class III in $16 \%$ cases. 9 Shrestha S and Shrestha RM analyzed malocclusion and occlusal characteristics in orthodontic patients of Kathmandu valley. They reported Class I malocclusion in $54.7 \%$, Class II in $36.9 \%$ and Class III in $8.4 \% .{ }^{10}$

Sharma JN reported prevalence of Class I, II and III malocclusions as $62.28 \%, 29.4 \%$.and $8.2 \%$ respectively in eastern Nepalese population. According to their study; the occlusal characteristics were: supernumerary teeth $2.9 \%$, ectopic eruptions $7.1 \%$, midline diastema $16 \%$, incisor crowding $52.9 \%$, spacing $30 \%$, tooth malformations $3.1 \%$, increased overjet $42.3 \%$ cases, anterior open bite 
$5.1 \%$ subjects, deep bite $40 \%$ and cleft lip and palate in $0.28 \%$ subjects. $^{8}$

Silva and Kang found prevalence of malocclusion among Latino adolescents of USA. They found more than $93 \%$ of the subjects having malocclusion." Among various studies on Caucasians; Krogman found the prevalence of malocclusion in $28 \%, 24.4 \%$ and $1.7 \%$ in Class I, II, III respectively and normal occlusion in $45.9 \%$ in children. Jackson and Brehm in the study among 6328 children and teenagers reported the prevalence of malocclusion as: normal occlusion in $16.6 \%$, Class I in $60.1 \%$, Class II in $22.8 \%$ and Class III in 0.5\%. Emrich et al in the study on 13475 adolescents reported normal occlusion in $54 \%$, Class I in $30 \%$, Class II in $15 \%$ and Class III in $1 \%$. Mills in the study among 1337 teenagers; reported normal occlusion in $17.5 \%$, Class I in $72.2 \%$, Class II in $6.6 \%$ and Class III in $3.7 \%$. A study on 651 Indian-American children and teenagers aged 6-18 years; revealed normal occlusion in 34.6\%; Class I in 53\%; Class II in $9.5 \%$ and Class III in $2.9 \%$. A study on 1700 Danish children and adolescents aged 9-18 years, reported normal occlusion in $14 \%$, Class I in $58 \%$, Class II in $24 \%$ and Class III in 4\%. ${ }^{1-5}$ A study on 398 men aged 21-25 years in Sweden reported the prevalence of malocclusion in $57 \%$. In this study; crowding, increased overjet and open bite were found in $43 \%, 10 \%$, and $8 \%$ cases respectively. ${ }^{6}$

Among the African samples, a study in 919 teenagers of 13-15 years in Kenya reported the prevalence of malocclusion was as high as $72 \%$. In this study; crowding, increased overjet and open bite were found in 19\%, $10 \%$, and $8 \%$ cases respectively. ${ }^{3}$
Baral $\mathrm{P}$ reported a comparative study on prevalence of malocclusion among Aryan and Mongoloid races of Nepal. It was found that Class I molar relation was seen in $61.3 \%$ in Aryan and 64\% in Mongoloid; Class II div 1 in $25.2 \%$ in Aryan and $17.9 \%$ in Mongoloid; Class II div 2 in $5.3 \%$ in Aryan and $2.5 \%$ in Mongoloid; Class III in $8.2 \%$ in Aryan and $15.6 \%$ in Mongoloid. Occlusal characteristics like crowding was seen in $46.6 \%$ Aryan and $48.1 \%$ Mongoloid; spacing in 9.9\% Aryan and $8.7 \%$ Mongoloid; crossbite in $10.4 \%$ Aryan and $17.8 \%$ Mongoloid; open bite in $10.6 \%$ Aryan and $18.4 \%$ Mongoloid and deep bite in $34.9 \%$ Aryan and $29.8 \%$ Mongoloid. It was concluded that there was difference in distribution of malocclusion pattern among different Nepalese races. ${ }^{12}$

\section{CONCLUSION}

The prevalence of malocclusion in western Nepalese subjects is Class I in $71.5 \%$, Class II div 1 in $20.7 \%$, Class II div 2 in $3.9 \%$ and Class III in $4.1 \%$. Crowding was seen more frequently than spacing, anterior cross bite cases were occurring more frequently than posterior cross bite cases and deep bite cases were more frequently occurring than open bite cases. Scissor bite was the least occurring occlusal characteristic. The present study showed no significant difference in gender dimorphism in prevalence and characteristics of malocclusion.

\section{REFERENCES}

1. Staley N R. Etiology and Prevalence of Malocclusion. In: Bishara SE. Textbook of Orthodontics. Philadelphia: Saunders; $2001: 84-104$.

2. Profit WR. Malocclusion and Dentofacial Deformity in Contemporary Society. Contemporary Orthodontics, 3rd ed. Missouri, Mosby; 2000:2-21.

3. Ng'ang'a PM, Ohito F, Ogaard B, Valderhaug J. The prevalence of malocclusion in 13-15 year-old children in Nairobi, Kenya. Acta Scand. 1996; 54:126-30.

4. Kapila S. Distribution of malocclusions in African and Asian children in Nairobi schools. Odontostomatol Trop. $1983 ; 6: 131-7$.

5. Ng'ang'a PM. A study of occlusion anomalies and teeth loss in children aged 13-15 in Nairobi. E Afr Med J 1991; 68:980-8.

6. Ingernall B, Mohlin B, Thilender B. Prevalence and awareness of malocclusion in Swedish men. Comm Dent Oral Epidemiol. $1978 ; 6: 308$.

7. Sazgara H, Rostami N, Maleki Z. The evaluation of occlusal interference pattern in students of Shahid Beheshti Faculty of Dentistry aged 18-25. Beheshti Univ Dent J. 1995; 20:39-46.

8. Sharma JN. Pattern of distribution of malocclusions in patients seeking orthodontic treatment at BPKIHS from Sunsari District of Nepal. Health Renaissance 2010; 8(2):93-6.

9. Shrestha BK, Yadav R, Basel P. Prevalence of malocclusion among high school students in Kathmandu valley. Orthod J Nep. 2012; 2(1):15.

10. Shrestha S, Shrestha RM. An analysis of malocclusion and occlusal characteristics in Nepalese orthodontic patients. Orthod J Nep. 2013; $3(1): 19-25$.

11. Silva RG, Kang DS. Prevalence of malocclusion among Latino adolescents. Am J Orthod Dentofac Orthop. 2001; $119(3): 313-5$.

12. Baral P. Prevalence of malocclusion in permanent dentition in Aryan and Mongoloid races of Nepal- A comparative study. Pak Oral J. $2013 ; 5(2): 57-9$ 